\title{
¿DEBE SER PUNIBLE LA INDUCCIÓN A LA PROSTITUCIÓN? ESTUDIO DE SU FUNDAMENTACIÓN, ESTRUCTURA DOGMÁTICA Y PROBLEMÁTICA
}

\author{
Juan Francisco Mendoza Perdomo \\ Universidad de Buenos Aires
}

\section{Resumen}

En este trabajo observaremos las razones que fundan la existencia legal del delito de inducción a la prostitución en un Estado social y democrático de Derecho, en el que se afirma, constitucionalmente, la existencia de la autonomía individual del ciudadano. A partir de allí y de la mano con el trascurrir histórico de este delito, ofrecido por la doctrina nacional de todas nuestras épocas, ofreceremos razones para indicar que responde al recorte de la libertad sexual de los ciudadanos, antes que a su tutela. Por último, se identificarán dos problemas de la dogmática penal en la estructura de imputación de este delito, que se suman a las razones críticas.

Palabras clave: prostitución, Derecho Penal, sanción penal, administración de justicia.

El autor: doctorando en Derecho. Docente universitario de la Universidad Santo Tomás y de la Universidad Católica de Colombia. Dirección postal: carrera 9 No. 53-58. Oficina 302. Correo electrónico: juanframendoza@gmail.com

Recibido: 3 de marzo de 2014; evaluado: 25 de abril de 2014; aceptado: 27 de mayo de 2014. 


\title{
SHOULD THE INDUCTION INTO PROSTITUTION BE PUNISHABLE? A STUDY ON ITS SUPPORTING STATEMENT, ITS DOGMATIC STRUCTURE AND ITS PROBLEMS
}

\author{
Juan Francisco Mendoza Perdomo \\ UniversidAd de Buenos Aires
}

\begin{abstract}
In this paper we will take a look at the reasons that support the legal existence of induction into prostitution as a crime in a Democratic and Social State of Rule of Law, where the existence of the individual autonomy of the citizen is constitutionally stated.
\end{abstract}

From this introduction point along with the historic happenings of this crime offered by the national doctrine of all our times, we present reasons to note this crime responds to a cut of the sexual freedom of citizens, rather than its protection.

Finally, we identify two problems of the legal dogmatic in the structure of imputation of this crime which are added up to the critical reasons.

Keywords: Prostitution, criminal law, criminal sanction, administration of justice.

About the author: Candidate to a Doctorate in Law. University professor at Universidad Santo Tomás and Universidad Católica de Colombia. Address: Carrera 9a No. 53-58 of. 302. E-mail: juanframendoza@gmail.com

Received: March 3, 2014; reviewed: April 25, 2014; accepted: May 27, 2014. 


\section{Introducción}

En su momento legislativo, el Derecho Penal pretende ofrecer buenas razones para la protección de bienes jurídicos que descansan, en muchos casos, en libertades fundamentales de rango constitucional. Tal protección se articula con la incriminación de conductas que, en apariencia, serían censurables por la sociedad, lo que legitima la intervención punitiva.

Muy a menudo se estima, con una suerte de presunción de legitimidad, que el legislador utiliza el Derecho para limitar las acciones de los hombres y extender tutela a las libertades más preciadas, sin parar mientes en las razones que pudo observar en un contexto ético y social.

El presente artículo examina, desde la historia del Derecho y el constitucionalismo contemporáneo, los argumentos esgrimidos por el legislador frente al delito de inducción a la prostitución. Nuestra hipótesis es que, en lugar de proteger la tutela de libertad, este tipo penal la recorta. En este análisis se recurrió al estudio de fuentes documentales primarias como la legislación y a fuentes secundarias por medio del uso de documentos de doctrina legal.

\section{Concepto de inducción a la prostitución}

La inducción a la prostitución, tratada en el Artículo 213 del Código Penal, ${ }^{1}$ es una conducta consistente en ejercer influencia psíquica en una persona para que esta adopte la decisión de practicar la prostitución por su cuenta y riesgo. Se trata de favorecer la resolución de otra persona de orientar su libertad sexual hacia prácticas sexuales que deriven en el pago de prestaciones o utilidades en favor del inducido y del inductor o a la satisfacción de necesidades sexuales a beneficio de un tercero. Con esto se puede afirmar que quien induce a la prostitución es un intermediario ${ }^{2}$ entre la víctima y un tercero, actual o potencial requirente de los contactos sexuales de aquella. De esta forma, la mediación del inductor le lleva a intervenir de manera

Inducción a la prostitución. Artículo modificado por el Artículo 8 de la Ley 1236 de 2008. El nuevo texto es el siguiente: "El que con ánimo de lucrarse o para satisfacer los deseos de otro, induzca al comercio carnal o a la prostitución a otra persona, incurrirá en prisión de diez (10) a veintidós (22) años y multa de sesenta y seis (66) a setecientos cincuenta (750) salarios mínimos legales mensuales vigentes". Colombia, Congreso de la República, Código Penal (Bogotá: Leyer, 2012), art. 213.

2 Jorge Enrique Valencia, Delitos contra la libertad, integridad y formación sexuales. 2a ed. (Bogotá: Legis, 2002), 102 
directa sobre la víctima, para que esta decida enmarcar sus contactos sexuales en los fines del tráfico sexual y la prostitución.

Así, la acción del inductor se restringe a determinar la libertad sexual del inducido, sin que las prácticas sexuales del inducido le favorezcan personalmente al inductor, esto es, sin que el inductor establezca contacto sexual con la víctima, pues se trataría de un conducta irrelevante para el Derecho y, a la postre, para el Derecho Penal, habida cuenta que la consecución de favor sexual por medio del convencimiento del favorecido hace a una acción lícita, que se inscribe en las acciones privadas de las personas dentro del umbral de la libertad de organizar los planes de vida.

Esta limitación a la persona del inductor estará estipulada por dos factores: la determinación utiliza medios distintos al engaño y la violencia, y la determinación procura intereses indirectos en el inductor.

En el primer factor, la conducta de inducir, de suyo psicológica, emplea medios como las promesas de beneficio, el halago de las condiciones físicas, el estímulo hacia el lucro, la promoción de un estatus o de una vida mejor y, como estrategias, buscan incidir en la libertad sexual, tras ofrecer razones que se suman a las personales del inducido o definen las existentes en él, para que funden su decisión final de sexualidad. Ajenos a estos mecanismos está el engaño, pues no es posible engañar a quien es mayor de edad y conoce el contenido y los alcances de la libertad sexual. Dicho de otra forma, si la libertad sexual existe como derecho formado y consolidado, no puede predicarse una distorsión del conocimiento previo al que se ha accedido para la prédica de esta clase de libertad. Distinto es que se recurra al engaño a menor de edad, pues se parte de la premisa de que aún está formando su libertad sexual; esta hipótesis se reprime con el delito de proxenetismo con menor de edad ${ }^{3}$ o que el medio sea la violencia exigida por el delito de constreñimiento a la prostitución, ${ }^{4}$ en el que la fuerza se define por la coacción que sujeta a la víctima a soportar el anuncio de un mal futuro o de un directo perjuicio, ${ }^{5}$ que vicia su voluntad frente a la decisión final de prostituirse.

El segundo factor hace referencia a la finalidad que el tipo penal designa al inductor y es el ánimo de lucro o la satisfacción de los deseos sexuales de otro. Tales ánimos, que dogmáticamente se nominarían como elementos subjetivos y complementan el

\footnotetext{
Colombia, Congreso de la República, Constitución Política (Bogotá: Leyer: 2012), art. 213

Colombia, Congreso de la República, Constitución Política, art. 214.

Valencia, Delitos contra la libertad, integridad y formación sexuales, 106.
} 
dolo del agente, le marginan de una relación sexual con la víctima, como la razón que subyace a su determinación, pues su interés es indirecto y no obedece a su influencia directa en el inducido, ya que se encamina a ser receptor de utilidades materiales o a ser facilitador del querer sexual de otros. La discontinuidad entre la acción inductiva y el factible beneficio propio o de otros son consideraciones de la acción del agente, que pueden materializarse sin su protagonismo sexual directo.

En otra época, el lucro percibido por el inductor era tenido como un delito autónomo, llamado delito de rufianismo, consistente en vivir en todo o en parte a expensas de la persona cuya prostitución explote, ${ }^{6}$ en tanto la satisfacción de los deseos sexuales de otro, conseguida con la intermediación del inductor, se conocía como el delito de celestinaje. ${ }^{7}$ No obstante, tal conducta era realizada no solo por medio de instigación, sino también de engaño, coacción y abuso de autoridad.

A diferencia de otras codificaciones, en el Código Penal de 1936 se exigía concurrencia de estos dos injustos como un solo elemento subjetivo. ${ }^{8}$ Así, la doctrina autorizada estimó que, además del dolo genérico, se requería un doble dolo específico, ${ }^{9}$ compuesto por el ánimo de lucro y la satisfacción de los deseos de otro que, como elementos cumulativos, debían darse en forma conjunta.

Ahora bien, en el mismo contexto, la doctrina que comentara el Código Penal referido comprendía la inducción a la prostitución como uno de los delitos de proxenetismo, que era el nombre asignado al Capítulo VI, enlistado dentro del Título XII "De los delitos contra la libertad y el honor sexuales". De esta forma, el proxenetismo, que en otras legislaciones como el Código de Napoleón de $1810^{10}$ recibía el nombre de lenocinio, contaba con grados, expresados en los nombres

6 Así se entiende en la doctrina española. José María Rodríguez Devesa, Derecho Penal español, Parte especial. 6a ed. (Madrid: S. L. Libros Dykinson, 1975), 188-189.

$7 \quad$ Así la doctrina española a la conducta descrita en el Artículo 425 bis a) del Código Penal español de 1928. Rodríguez Devesa, Derecho Penal español, 185

8 "El que con el ánimo de lucrarse y para satisfacer los deseos de otro, induzca al comercio sexual o a la prostitución a una persona honesta, estará sujeto a las siguientes penas: [...]". Colombia, Congreso de la República, Ley 95 de 1936, "Sobre Código Penal" (Bogotá: Diario Oficial No. 23316, 24 de octubre de 1936), art. 327.

9 Fue llamado, además, el doble elemento moral. Luis Carlos Pérez, Derecho Penal colombiano, Parte especial. Volumen II (Bogotá: Temis, 1957), 370; Pedro Pacheco Osorio, Derecho Penal especial, Tomo II. 2a ed. (Bogotá: Temis, 1977), 346.

10 El Código Penal francés indicaba que el lenocinio era "la acción de excitar, favorecer o facilitar habitualmente la prostitución o la corrupción de jóvenes de uno y otro sexo, menores de veintiún años". Parlamento Francés, "Código Penal", http://perso.unifr.ch/derechopenal/assets/files/legislacion/1_20080616_45.pdf (acceso octubre 22, 2012), art. 334. 
de los agentes del delito: el corruptor, ${ }^{11}$ el rufián y el traficante de blancas. ${ }^{12}$ El corruptor era el agente del delito de inducción a la prostitución del Artículo 327; el rufián, el sujeto del Artículo 331 y el traficante de blancas, el descrito en el numeral 1 del Artículo 330, todos del Código de 1936.

El injusto de estas infracciones se encuentra recogido de manera distinta en el Código Penal vigente, toda vez que no existe la conducta autónoma de rufianismo, ya que la misma constituye una circunstancia de agravación punitiva de los delitos de explotación sexual (inducción a la prostitución, ${ }^{13}$ proxenetismo con menor de edad ${ }^{14} \mathrm{y}$ constreñimiento a la prostitución), ${ }^{15}$ verificada en el Artículo 213.6; por su parte, la corrupción sigue conformando autonomía como delito, al verterse en el citado Artículo 213 y la trata de blancas, que taxativamente se denomina trata de personas, se concreta en el Artículo 188A, como un delito contra el bien jurídico de la libertad individual. No obstante, podría afirmarse que la antigua trata de blancas sigue vigente en la actual legislación, cuando se le consagra como circunstancia de agravación en el numeral 2 del citado Artículo 216, relativo a situaciones específicas de mayor pena en los delitos de la explotación sexual, nombre que lleva el capítulo que los acopia.

En su hora, en la tipificación de la inducción a la prostitución, el Artículo 308 del Código Penal de 1980, que guarda el mismo lenguaje del actual Código Penal, utiliza una fórmula alternativa para la concurrencia del elemento subjetivo y lo escinde en ánimo de lucro "o" satisfacción de los deseos sexuales de otro. A esta disyunción en el lenguaje normativo, la doctrina se opuso: de un lado, resalta que el favorecimiento de los deseos sexuales debe concebirse como necesaria en todo delito de proxenetismo, porque es, además, una característica esencial de esta conducta. ${ }^{16}$ De otro lado, en apuesta a un propósito común, se afirmó que en todas las formas de proxenetismo acude el fin del lucro del agente, lo que "conlleva el sello de la ilicitud". ${ }^{17}$

\footnotetext{
11 Al corruptor, Luis Carlos Pérez lo llamó genéricamente proxeneta, por un incurrir en la difícil diferenciación entre corrupción y proxenetismo. Pérez, Derecho Penal colombiano, 369.

12 Luis Gutiérrez Jiménez, Derecho Penal especial (Bogotá: Temis, 1965), 353-355.

13 Colombia, Congreso de la República, Código Penal, art. 213.

14 Colombia, Congreso de la República, Código Penal, art. 213A.

15 Colombia, Congreso de la República, Código Penal, art. 214.

16 Antonio Vicente Arenas, Comentarios al Código Penal colombiano. Tomo II. 6a ed. (Bogotá: Temis, 1986), 359.

17 Pérez, Derecho Penal colombiano, 369; de forma similar, Gustavo Rendón Gaviria, Derecho Penal colombiano, Parte especial. Volumen I. 3a ed. (Bogotá: Temis, 1973), 228.
} 


\section{El objeto de protección}

El objeto de protección en este delito se explica desde la conducta del inductor, que afirmáramos intermedia para convencer a la víctima de orientar su sexualidad a la prostitución.

El intermediario, que es un verdadero gestor de los contactos sexuales de la víctima, cercena con su obrar la libre toma de decisiones del sujeto en su esfera de autodeterminación sexual. ${ }^{18}$ De tal manera, la conducta del intermediario lesiona la libertad sexual de la persona que se prostituye, ${ }^{19}$ pues de manera eficaz le sugiere la idea de comerciar con su cuerpo o darse a la prostitución.

No puede ser otra que la libertad para organizar una vida sexual la que se lesione, puesto que la integridad y la formación sexuales, que integran la taxatividad del bien jurídico consagrado en el Código Penal, se comprenden como intereses que ya se han verificado en la víctima de este delito, excepción hecha de los sujetos pasivos que cuenten con minoría de edad.

Si la libertad sexual o para decidir sobre la vida sexual resulta ser una especie del plus de libertades constitucionales, que con la fisonomía de derechos fundamentales $^{20}$ pueden ejercer los ciudadanos, tal libertad debe comprender una eficiente cuantía de conocimiento en cabeza del ciudadano, que le permita la realización de su derecho de elegir sus contactos sexuales. Quiere decir que la libertad sexual solo será lesionada si se comprenden el concepto, el contenido y los alcances de los contactos sexuales que cualitativamente la explican; esto es, que para lesionarse la libertad sexual deben afirmarse como preexistentes la formación e integridad sexual que, a más de intereses, constituyen presupuestos de la libertad.

La integridad y la formación sexuales son dos intereses que el legislador de 2000 conjugó con la libertad sexual para conformar un bien jurídico de carácter complejo y se apartó, por fortuna, de las denominaciones que, con marcado acento moral, preveían como bien jurídico, junto con la libertad sexual, valores como la moral

18 Fermín Morales Prats y Ramón García Albero, "Delitos contra la libertad sexual" en Comentarios a la parte especial del Derecho Penal, dir. Gonzalo Quintero Olivares (Pamplona: Aranzadi, 1996), 266.

19 Francisco Muñoz Conde, Derecho Penal, Parte especial. 1la ed. (Valencia: Tirant lo Blanch, 1996), 209.

20 Colombia, Congreso de la República, Constitución Política, art. 16. 
públicaa (Códigos Penales 1837 y 1890), el honor sexual (Código Penal de 1936) y el pudor sexual (Código Penal de 1980).

La integridad sexual es entendida hoy día como la identidad sexual de una persona, ${ }^{22}$ que le permite distinguirse de los demás como un ser sexualmente distinto, en clave ética. Un ser ético, además de ser antropológico, debe incorporar en su individualidad un definido programa de comprensión de la vida sexual en sociedad. A esta comprensión solo se arriba por medio de la formación sexual, obtenida dentro del contexto social, que abarca la enseñanza, el aprendizaje y la experiencia. ${ }^{23}$

Queda claro que a la integridad sexual le precede la formación sexual y que esta última constituye el interés jurídico que permite edificar los riesgos lesivos a la libertad sexual, al accederse al conocimiento de las consecuencias que pueden resultar negativas cuando se ejerce la propia libertad.

Los planes y proyectos de vida de todo individuo deben considerar lo positivo y lo negativo en su ejecución, de modo que la libertad, incluida la sexual, sea la inflexión de los intereses y valores que formen al individuo. Con esto, puede definirse la libertad sexual como la facultad de evitar contactos sexuales con quien no se quiere o en circunstancias no deseadas ${ }^{24} \mathrm{o}$ la facultad de oponerse a tener relaciones sexuales en contra de la voluntad. ${ }^{25}$ Este concepto contrasta con el de la libertad sexual positiva, como la facultad de disponer del cuerpo con fines sexuales. ${ }^{26}$

\section{El sujeto pasivo}

El sujeto pasivo de la conducta de inducción se sitúa en un rol general de ciudadano, a quien se impone el deber de evitar lesionar en bienes jurídicos de otros y también los suyos. Con esta premisa, el ciudadano inducido es garante de la indemnidad

$21 \quad$ Nuestros códigos penales decimonónicos (de 1837 en la Nueva Granada; de 1953 en el Estado de Cundinamarca; de 1973 en los Estados Unidos de Colombia y de 1890 en la Regeneración) no protegieron la libertad sexual dentro del rubro de la "moral pública". Empero, la doctrina de la época dejaba ver que la existencia de los delitos de proxenetismo, llamados de "alcahuetería", se encaminaban a tutelar a las "personas faltas de raciocino y experiencia", como los menores de edad. José Vicente Concha, Tratado de Derecho Penal. 6a ed. (Bogotá: Librería Americana, 1896), 277.

22 Luis Fernando Tocora, Derecho Penal especial. 9a ed. (Bogotá: Ediciones Librería El Profesional, 2002), 242.

23 Tocora, Derecho Penal especial, 242.

24 Tocora, Derecho Penal especial, 243.

25 Lisandro Martínez Zúñiga, Derecho Penal Sexual. 2a ed. (Bogotá: Temis, 1977), 110.

26 Humberto Barrera Domínguez, Delitos sexuales: conforme al Título XI del Código de 1980 (Bogotá: Visión, 1984), 63; Humberto Barrera Domínguez, Delitos sexuales (Bogotá: Temis, 1963), 58. 
de su libertad sexual, cuando quiera que en el ámbito de su competencia deberá evitar los riesgos ínsitos a la libertad de organizar una vida sexual.

Empero ¿si al sujeto se le induce, sin engaño y sin violencia, a orientar su libertad — que no anularla - hacia la prostitución o el comercio sexual, podrá predicarse una lesión al bien jurídico? La respuesta habrá de ser negativa por varias razones:

a. La prostitución y el comercio carnal son actividades humanas lícitas, ${ }^{27}$ por lo menos en la inmensa mayoría de los países del mundo que sigue la llamada tendencia abolicionista —en la cual no se prohíbe penalmente su realización — o en la reglamentarista — en la que la prohibición es de carácter policivo, previa reglamentación y control por las autoridades de salud pública—. ${ }^{28}$

Con ese denominador común, la doctrina entiende que la prostitución y el comercio carnal acusan diferencias; para ello se indica que la prostitución es la venta de actos sexuales, de manera pública y habitual. ${ }^{29} \mathrm{El}$ hecho de que se identifique por ser pública hace al ofrecimiento público y la persona está expuesta o se ofrece públicamente al comercio sexual, aunque las prestaciones sexuales se llevan a cabo de modo clandestino. ${ }^{30}$ Por su parte, el carácter de habitualidad de la prostitución se entiende como la repetición no solo de las prestaciones sexuales, que responden al ejercicio permanente del oficio, sino a la sostenible publicidad de la concupiscencia, esto es, a personas indeterminadas en su identidad y número. ${ }^{31}$

Este rasgo colectivo que fundamenta la habitualidad ${ }^{32}$ permite distinguir la prostitución del comercio carnal, pues este tráfico de contactos sexuales se efectúa a cambio de una ventaja de cualquier especie, lo que supone una entrega recíproca de favores. Allí se indica que cuando ese intercambio prestacional deviene en medio para el sostenimiento, se trata de meretricio o, mejor, de prostitución. ${ }^{33}$ Además, se considera que otro facto de distinción es que en la prostitución los receptores

\footnotetext{
27 Entre nosotros, Tocora, Derecho Penal especial, 280. De la doctrina extranjera, Muñoz Conde, Derecho Penal, 206.

28 Así lo explica Bustos Ramírez en referencia al tratamiento dado por el Derecho español a la prostitución. Juan Bustos Ramírez, Manual de Derecho Penal, Parte especial. 2a ed. (Barcelona: Ariel, 1991), 127.

29 Tocora, Derecho Penal especial, 279.

30 Pérez, Derecho Penal colombiano, 372-373.

31 Tocora, Derecho Penal especial, 279-280

32 Mirentxu Corcoy Bidasolo, dir., Manual práctico de Derecho Penal, Parte especial. 2a ed. (Valencia: Tirant lo Blanch, 2004), 348.

33 Pérez, Derecho Penal colombiano, 373.
} 
del contacto sexual son personas indeterminadas, mientras en el comercio carnal la entrega del cuerpo se hace con una persona nominada por el interés del pago. ${ }^{34}$

Sin embargo, la prostitución y el comercio carnal configuran un conflicto social ajeno al Derecho Penal, pues con estas actividades no hay vulneración de un bien jurídico-penal que demande la intervención punitiva estatal. Así, el tráfico sexual será un asunto de control social no punitivo, en el que su rechazo o censura se deben a la libertad sexual de quien desea y le permite no solo disponer de su sexualidad, sino lucrarse de la misma, como una especie de derecho fundamental a elegir la profesión u oficio. ${ }^{35}$

b. Si la prostitución y el comercio carnal son actividades lícitas que se contraen a la esfera individual de la persona humana cuando esta puede disponer de su libertad de organizar su vida sexual y de procurar sus ingresos económicos por medio de esta actividad, ipuede inducirse a un mayor de 18 años a que autolesione su libertad sexual?

La respuesta habrá de ser negativa, pues si se asume que el tráfico sexual propio es una actividad contractual de riesgo social, este riesgo es, a la postre, permitido, cuando quiera que no se lesionen o comprometan libertades de órbitas ajenas. Mucho menos podría afirmarse que la intervención del Derecho Penal respecto a la prostitución deriva de inmenso amparo de la libertad sexual, ya que, por mucho que desborden el límite de la moral, los negocios o acuerdos que versen sobre prestaciones sexuales forman parte de la autonomía individual, que se refleja en la identidad o personalidad sexual y en la libertad de seleccionar el oficio del tráfico sexual como una actividad humana libre que puede ser objeto de contratación. ${ }^{36}$

Un dato histórico del delito de inducción a la prostitución puede ser ilustrativo de este ámbito de competencia de víctima. Se trata de la cualificación de "honestidad" que debía ostentar la persona del sujeto pasivo de este delito, según el tenor de los Artículos 327 del Código Penal de 1936 y 308 del Código Penal de 1980.

34 Arenas, Comentarios al Código Penal colombiano, 361.

35 Colombia, Congreso de la República, Constitución Politica, art. 26.

36 Frente al caso de los trabajadores sexuales, la Corte Constitucional expresó: "Habrá contrato de trabajo y así debe ser entendido, cuando el o la trabajadora sexual ha actuado bajo plena capacidad y voluntad, cuando no hay inducción ninguna a la prostitución, cuando las prestaciones sexuales y demás del servicio, se desarrollen bajo condiciones de dignidad y libertad para el trabajador y por supuesto cuando exista subordinación limitada por el carácter de la prestación, continuidad y pago de una remuneración previamente definida [...]". Colombia, Corte Constitucional. Sentencia T-629 de 13 de agosto de 2010. M. P. Juan Carlos Henao Pérez. 
La doctrina indicaba que la persona inducida debía contar con la condición de ser considerada socialmente como honesta, esto es, que goce de buena fama en su círculo social ${ }^{37}$ que la honestidad era la ausencia de reproche a su honor sexual; ${ }^{38}$ la carencia de honor sexual o de un buen concepto de su actuar sexual, ${ }^{39} \mathrm{o}$ en la ausencia de abstinencia corporal a planes sexuales, que genera su corrección en la actitud moral y material con lo erótico. ${ }^{40}$ No obstante la falta de convergencia en los conceptos de honestidad, sí se entendió que la "persona honesta" era quien no había elegido en su plan de vida sexual el ejercicio de la prostitución o el comercio carnal, habida cuenta de que no podía corromperse -inducirse a la prostitución- a quien ya estuviera en ella. ${ }^{41}$

Esta idea precisa que a quien decide con libertad traficar con su sexualidad no puede ser lesionado en su libertad sexual, con excepción de los casos en donde el sujeto pasivo es menor de edad, como en el delito de proxenetismo con menor de edad o en pasible de violencia intimidante, como en el delito de constreñimiento a la prostitución. Así, la única razón de la intervención penal de la prostitución de mayores de edad será la que favorezca la lesión a la libertad, mediante la obligación en la persona de la víctima. ${ }^{42}$

Este ejercicio de libertad sexual por el propio titular de bien jurídico se explica dogmáticamente por la competencia de la víctima: el principio de autorresponsabilidad, entendido desde la idea de que cada quien es responsable por sus propios actos, es decir, es responsable personalmente por la libertad. ${ }^{43}$ Esto descansa en el modelo social, de base constitucional, que fija que los individuos son autónomos. ${ }^{44}$ En consecuencia, a todo ciudadano le corresponde un ámbito de organización propia de su plan de vida — que incluye su identidad y libertad sexual—y le corresponderá, por ser titular de su autoorganización, la responsabilidad y los costos que deriven de esa organización. ${ }^{45}$

\footnotetext{
Arenas, Comentarios al Código Penal colombiano, 358.

Pacheco Osorio, Derecho Penal especial, 343.

Barrera Domínguez, Delitos sexuales, 212.

Pérez, Derecho Penal colombiano, 370.

Rendón Gaviria, Derecho Penal colombiano, 229.

Muñoz Conde, Derecho Penal, 209.

Manuel Cancio Meliá, Conducta de la víctima e imputación objetiva en Derecho Penal: estudio sobre los ámbitos de responsabilidad de víctima y autor en actividades arriesgadas. 2a ed. (Barcelona: J. M. Bosch, 2001), 278-279.

44 Entre nosotros, la referencia constitucional será el derecho al libre desarrollo de la personalidad, concretado en el Artículo 16 de la Constitución Política.

45 Cancio Meliá, Conducta de la víctima e imputación objetiva en Derecho Penal, 279.
} 
Si aun al conocer sus costos y que el ordenamiento jurídico autoriza el tráfico sexual - pese a tutelar la libertad sexual - el titular de esa organización sexual decide hacerse responsable por su propia libertad, estaremos ante un caso del ejercicio de la llamada libertad negativa, entendida como aquella especie de libertad de la que goza cada uno de nosotros cuando otros no interfieren en nuestra acciones. ${ }^{46}$ Sobre el concepto de libertad negativa es paradigmática la sentencia constitucional de la "dosis personal", que afirmó:

Cuando el Estado resuelve reconocer la autonomía de la persona, lo que ha decidido, ni más ni menos, es constatar el ámbito que le corresponde como sujeto ético: dejarla que decida sobre lo más radicalmente humano, sobre lo bueno y lo malo, sobre el sentido de su existencia [...]. Se trata de que cada persona elija su forma de vida responsablemente, y para lograr ese objetivo, es preciso remover el obstáculo mayor y definitivo: la ignorancia. Sin compartir completamente la doctrina socrática de que el único mal que aqueja a los hombres es la ignorancia, porque cuando conocemos la verdad conocemos el bien y cuando conocemos el bien no podemos menos que seguirlo, sí es preciso admitir que el conocimiento es un presupuesto esencial de la elección libre y si la elección, cualquiera que ella sea, tiene esa connotación, no hay alternativa distinta a respetarla, siempre que satisfaga las condiciones que a través de esta sentencia varias veces se han indicado, a saber: que no resulte atentatoria de la órbita de la libertad de los demás y que, por ende, si se juzga dañina, sólo afecte a quien libremente la toma. ${ }^{47}$

Con estas razones se afirma que la inducción a la prostitución, como delito, responde a una limitación de la autonomía y la libertad del individuo, al que indirectamente se sanciona por el ejercicio del tráfico sexual. Se trata de una limitación al derecho fundamental a la libertad sexual — como corolario de la autonomía individual— por la protección del bien jurídico de la libertad sexual. El telón de fondo de la intervención penal enseña que se incrimina la prostitución y el comercio carnal por un Estado paternalista, de carácter moralizante, que encuentra razones en una idea de moral social por la que se procura la prevención general del tráfico sexual. ${ }^{48}$

46 Eduardo Barbarosch, Teorías de la justicia y la metaética contemporánea (Buenos Aires: Buenos Aires La Ley, 2011), 81

47 Colombia, Corte Constitucional, Sentencia C-221 de 5 de mayo de 1999, M. P. Carlos Gaviria Díaz.

48 Bustos Ramírez, Manual de Derecho Penal, 127. 
Ya desde el siglo XIX nuestra doctrina refería que lo que establecen las normas relativas a la inducción a la prostitución son verdaderos castigos a la inmoralidad. ${ }^{49}$ Es posible destacar, entonces, que la inducción a la prostitución abandona la protección de la libertad sexual y muda este bien jurídico por la antigua moral pública, que se tutelaba de modo legítimo en otro contexto social.

El cambio de contexto social, como base de los conflictos administrados por el Derecho Penal, ha demandado del legislador la supresión de conductas típicas que en otras épocas se consideraron lesivas de bienes jurídicos o que, por otra vía, la jurisprudencia adopte nuevas pautas interpretativas en busca de justicia material. Un ejemplo de esto fue la derogatoria del delito de estupro, que estuvo tipificado en el Código Penal de 1936 y que sirviera también como ejemplo a la jurisprudencia penal colombiana para ilustrar la transformación del material social con el que se crean las normas penales. Esto expresó la Corte: ${ }^{50}$

Ese progreso de la nación ha obligado al Estado a dejar atrás de manera gradual aquellos períodos de acentuado proteccionismo para pasar a fases donde se ofrece una mayor libertad de interacción de las personas, reconociendo así que son individuos con posibilidad de discernimiento suficiente para sobreponerse a ciertas mentiras o engaños propios de la dinámica social.

Un ejemplo de esa elasticidad estatal ha sido la despenalización del estupro (denominada estafa sexual), cuya estructuración se asentaba, precisamente, en la realización de actos engañosos para la obtención del acceso carnal con persona mayor de catorce años y menor de dieciocho. En ese contexto, se consideró que los individuos de dichas edades presentan actualmente una capacidad intelectual apta para consentir libremente una relación sexual.

Por todo, al no haber lesión a bien jurídico alguno cuando se ejerce la autodeterminación, ${ }^{51}$ no se legitima intervención jurídica alguna y menos aún de carácter penal. ${ }^{52}$

Concha, Tratado de Derecho Penal, 277.

50 Se trató de la sentencia en la cual la Corte implementó la doctrina de la imputación objetiva por posición de garante del contratante en los negocios jurídicos de los que pueda deducirse un delito de estafa. Colombia, Corte Suprema de Justicia, Sala de Casación Penal, Sentencia de 10 de junio de 2008, Proceso No. 28693, M. P. María del Rosario González de Lemos.

51 Antonio José Cancino, Obras completas, Tomo III (Bogotá: Ediciones Jurídicas Gustavo Ibáñez, 1999), 225.

52 Tocora, Derecho Penal especial, 280. 


\section{La intervención en el delito: dos problemas dogmáticos}

A los anteriores argumentos que cuestionan la existencia del delito de inducción a la prostitución pueden agregarse otras dos razones de índole dogmática que utilizan las lógicas de la teoría jurídica del delito en lo referente a la intervención de personas en el delito. Veamos:

1. La precisión del concepto de autor, como el paradigma de la intervención delictiva, se ha construido a partir de su idea diferencial con la participación, para lo cual proponen diversas teorías que ofrecen utilidad para precisar nociones como la coautoría y la participación en sentido estricto.

Si se acude a una valoración moral de justicia, la comunidad dirige mayor censura al autor del delito porque, contrario al partícipe, es quien hace más por la comisión del delito, ${ }^{53}$ es decir, cuantitativamente, el autor genera un mayor desvalor con su conducta. Este valor moral responde al principio de proporcionalidad concreta como principio orientador de la pena,${ }^{54}$ lo que explica el hecho de que no resulte adecuado imponer la misma pena a autores y partícipes.

El autor será el vértice de la participación criminal, pues desarrolla la actividad principal, al punto de que la doctrina habla de la pertenencia del delito a él o compartida con otros, que le permiten su estatus de sujeto principal en el delito. ${ }^{55}$ En esa medida, los tipos penales son la expresión de una prohibición que puede ser contravenida por el hecho de un autor como de un partícipe, a quien se justifica su castigo por intervenir, sin ser autor, en el hecho punible de este. Esto permite diferenciar al autor del partícipe en el delito, como bien lo hace el legislador nacional mediante la cláusula general de participación, contenida en la parte general del Código Penal, ${ }^{56}$ en el que admite la realización del delito por determinadores o cómplices.

Si se asume de lege data que el delito debe ser realizado por un autor y que los partícipes - determinadores o cómplices- pueden intervenir en él ¿resultaría válido que el mismo legislador tipifique conductas en las que solo se permita,

\footnotetext{
Juan Fernández Carrasquilla, Derecho Penal, Parte general, Tomo III (Bogotá: Ibáñez, 2012), 788-789.

Colombia, Congreso de la República, Constitución Política, art. 4.

Paradigmático. Santiago Mir Puig, Derecho Penal, Parte general, 9a ed. (Montevideo: BdeF, 2011), 132.

Colombia, Congreso de la República, Código Penal, art. 29.
} 
taxativamente, la intervención de determinadores a quienes se les tratara punitivamente como al autor?

La respuesta ha de ser negativa, pues la construcción de un concepto unitario de autor en un tipo penal desprecia el principio de proporcionalidad aludido, que aspira, en el principio de diferencia, que las personas reciban un trato desigual, pero razonable en ciertas situaciones, como cuando se hace menos por el delito. Este es el caso del delito de inducción a la prostitución, en el que solo se admite la intervención delictiva de un determinador que, al ser un partícipe, recibe la pena de un autor.

2. La participación es la intervención en un hecho ajeno, por lo que presupone la existencia de un autor y de un hecho principal al cual se accede. Si el partícipe tiene un papel secundario en el delito, porque depende de la autoría de otro, se justifica un tratamiento atenuado en el marco penal. Esto se denomina principio de accesoriedad y explica una relación de dependencia de la participación con respecto a un hecho principal, que es aquello en lo que se participa. ${ }^{57}$

La accesoriedad, cualitativamente entendida, exige que el hecho principal —del autor - tenga sentido delictivo y acoge, con esto, la llamada accesoriedad limitada; para ello, basta un injusto del autor, esto es, hecho típico —una acción subsumida por un tipo previsto como delito en la ley-y antijurídico —una acción lesiva y antinormativa - De forma paralela, la accesoriedad cuantitativa exige que el hecho haya sido, cuando menos, ejecutado por el autor, para que el partícipe pueda ser sancionado.

Un marco conceptual del principio de accesoriedad será funcional si garantiza que solo sería punible la participación en una persona en un injusto penal que haya sido realizado por el autor, vale decir, que el hecho típico debe haberse ejecutado en sus elementos por el autor, según la cláusula del Artículo 26 de la Constitución Política. ${ }^{58}$

Este presupuesto de la imputación del delito a un partícipe, como el determinador de la prostitución, es inobservado en la estructura del delito comentado, por la manera como se quiebra el principio de accesoriedad en sus dos variantes:

57 Enrique Peñaranda Ramos, La participación en el delito y el principio de accesoriedad (Madrid: Tecnos, 1990), 326-327.

58 Peñaranda Ramos, La participación en el delito y el principio de accesoriedad, 327. 
cualitativa, toda vez que se conmina la conducta de un inductor que participa en unas conductas como la prostitución y el comercio carnal, que ya se precisó no son comportamientos tipificados en la ley como delito y mucho menos lesivos de bienes jurídico-penales. Y cuantitativa, pues no se puede ser partícipe de conductas que, a más de lícitas, no se han ejecutado al tiempo de la inducción.

Basados en estas precisiones dogmáticas que afirman las garantías de legalidad y culpabilidad de las personas que intervienen personalmente en el delito, se diría, en comunidad con lo dicho en la fundamentación de este tipo penal, que la existencia de la inducción a la prostitución recorta la libertad sexual por la protección de la libertad sexual.

\section{Referencias}

Arenas, Antonio Vicente. Comentarios al Código Penal colombiano. Tomo II. 6a ed. Bogotá: Temis, 1986.

Barbarosch, Eduardo. Teorías de la justicia y la metaética contemporánea. Buenos Aires: Buenos Aires La Ley, 2011.

Barrera Domínguez, Humberto. Delitos sexuales. Bogotá: Temis, 1963.

Barrera Domínguez, Humberto. Delitos sexuales: conforme al Título 11 del Código de 1980. Bogotá: Visión, 1984.

Bustos Ramírez, Juan. Manual de Derecho Penal. Parte especial. 2a ed. Barcelona: Ariel, 1991.

Cancino, Antonio José. Obras completas. Tomo III. Bogotá: Ediciones Jurídicas Gustavo Ibáñez, 1999.

Cancio Meliá, Manuel. Conducta de la víctima e imputación objetiva en Derecho Penal: estudio sobre los ámbitos de responsabilidad de víctima y autor en actividades arriesgadas. 2a ed. Barcelona: J. M. Bosch, 2001.

Colombia, Congreso de la República. Código Penal. Bogotá: Leyer, 2012.

Colombia, Congreso de la República. Constitución Politica. Bogotá: Leyer, 2012.

Colombia, Congreso de la República. Ley 95 de 1936, "Sobre Código Penal". Bogotá: Diario Oficial No. 23316, 24 de octubre de 1936.

Colombia, Corte Constitucional. Sentencia C-221 de 5 de mayo de 1999. M. P. Carlos Gaviria Díaz.

Colombia, Corte Constitucional. Sentencia T-629 de 13 de agosto de 2010. M. P. Juan Carlos Henao Pérez.

Colombia, Corte Suprema de Justicia, Sala de Casación Penal. Sentencia de 10 de junio de 2008, Proceso No. 28693. M. P. María del Rosario González de Lemos. 
Concha, José Vicente. Tratado de Derecho Penal. 6a ed. Bogotá: Librería Americana, 1896. Corcoy Bidasolo, Mirentxu, dir. Manual práctico de Derecho Penal. Parte especial. 2a ed. Valencia: Tirant lo Blanch, 2004.

Fernández Carrasquilla, Juan. Derecho Penal. Parte general. Tomo III. Bogotá: Ibáñez, 2012. Gutiérrez Jiménez, Luis. Derecho Penal especial. Bogotá: Temis, 1965.

Martínez Zúñiga, Lisandro. Derecho Penal Sexual. 2a ed. Bogotá: Temis, 1977.

Mir Puig, Santiago. Derecho Penal. Parte general. 9a ed. Montevideo: BdeF, 2011.

Morales Prats, Fermín y Ramón García Albero. "Delitos contra la libertad sexual" en Comentarios a la parte especial del Derecho Penal, dirigido por Gonzalo Quintero Olivares, 1113-1129. Pamplona: Aranzadi, 1996.

Muñoz Conde, Francisco. Derecho Penal. Parte especial. 1 la ed. Valencia: Tirant lo Blanch, 1996.

Pacheco Osorio, Pedro. Derecho Penal especial. Tomo II. 2a ed. Bogotá: Temis, 1977.

Parlamento Francés. "Código Penal", http://perso.unifr.ch/derechopenal/assets/files/ legislacion/1_20080616_45.pdf (acceso octubre 22, 2012)

Peñaranda Ramos, Enrique. La participación en el delito y el principio de accesoriedad. Madrid: Tecnos, 1990.

Pérez, Luis Carlos. Derecho Penal colombiano. Parte especial. Volumen II. Bogotá: Temis, 1957.

Rendón Gaviria, Gustavo. Derecho Penal colombiano. Parte especial. Volumen I. 3a ed. Bogotá: Temis, 1973.

Rodríguez Devesa, José María. Derecho Penal español. Parte especial. 6a ed. Madrid: S. L. Libros Dykinson, 1975.

Tocora, Luis Fernando. Derecho Penal especial. 9a ed. Bogotá: Ediciones Librería El Profesional, 2002.

Valencia, Jorge Enrique. Delitos contra la libertad, integridad y formación sexuales. 2a ed. Bogotá: Legis, 2002. 